\title{
An indicator-based methodology for assessing resilience in urban mobility
}

DOI:

10.1016/j.trd.2019.01.004

\section{Document Version}

Accepted author manuscript

Link to publication record in Manchester Research Explorer

\section{Citation for published version (APA):}

da Mata Martins, M. C., Rodrigues da Silva, A. N., \& Pinto, N. (2019). An indicator-based methodology for assessing resilience in urban mobility. Transportation Research Part D: Transport and Environment. https://doi.org/10.1016/j.trd.2019.01.004

\section{Published in:}

Transportation Research Part D: Transport and Environment

\section{Citing this paper}

Please note that where the full-text provided on Manchester Research Explorer is the Author Accepted Manuscript or Proof version this may differ from the final Published version. If citing, it is advised that you check and use the publisher's definitive version.

\section{General rights}

Copyright and moral rights for the publications made accessible in the Research Explorer are retained by the authors and/or other copyright owners and it is a condition of accessing publications that users recognise and abide by the legal requirements associated with these rights.

\section{Takedown policy}

If you believe that this document breaches copyright please refer to the University of Manchester's Takedown Procedures [http://man.ac.uk/04Y6Bo] or contact uml.scholarlycommunications@manchester.ac.uk providing relevant details, so we can investigate your claim.

\section{OPEN ACCESS}




\title{
An indicator-based methodology for assessing resilience in urban mobility
}

\author{
Marcel Carlos da Mata Martins \\ Department of Transportation Engineering, São Carlos School of Engineering, \\ University of São Paulo \\ Av Trabalhador Sãocarlense, 400, São Carlos SP, Brazil \\ Telephone: +551633739595 \\ E-mail: mcm-mata@hotmail.com
}

Antônio Nélson Rodrigues da Silva (correponding author)

Department of Transportation Engineering, São Carlos School of Engineering, University of São Paulo

Av Trabalhador Sãocarlense, 400, São Carlos SP, Brazil

Telephone: +551633739595

E-mail: anelson@sc.usp.br

Nuno Pinto

Spatial Policy and Analysis Lab, Manchester Urban Institute, The University of Manchester

Oxford Rd, Manchester M13 9PL, United Kingdom

Telephone: +441612752729

E-mail: nuno.pinto@manchester.ac.uk

\begin{abstract}
Resilience is an increasingly more important concept to understand the response urban systems are able to deliver to endogenous and exogenous shocks in the current context of climate change and socioeconomic uncertainty. Urban mobility, a fundamental component of urban systems, is naturally sensitive to shocks with significant impacts on daily life of individuals and businesses. The concept of resilience in urban mobility is under intensive research with increasingly more sophisticated approaches and methods being developed to assess resilience in transport modes due to different shocks. The literature is, however, absent on applications aimed at using simpler mobility indicators that are used and validated in urban mobility planning processes in the context of lack of
\end{abstract}


data or expertise. We propose a resilience evaluation method that uses commonly available origin-destination (OD) datasets to evaluate an overall indicator of resilience. We consider the possibility of trips made in motorised modes to be transferred to active modes in the event of a disruption of the mobility system. Results of the application of the method to two urban areas in Brazil show that each one has a specific pattern of mode change that is related to the OD patterns. The spatial distribution of trips shows the relative importance of resilient trips in the urban area. Finally, different levels of income have different sensitivity to the variation of resilience.

Keywords: urban mobility, resilience, mobility planning, accessibility, Brazil

\section{INTRODUCTION}

Holling (1973) first introduced the term resilience to understand the capacity of ecosystems to return to their initial states when subjected to perturbations. More recently, Walker et al. (2004), looking at increasingly trendy ideas of adaptability and transformability, defined resilience as

"the capacity of a system to absorb disturbance and reorganize while undergoing change so as to still retain essentially the same function, structure, identity, and feedbacks" (Walker et al., 2004, p. 4)

The clarity of the concept has made it a key idea to address planning, design and use of the most important systems in the incoming context of more frequent disruptions caused by multiple events, most notably as a consequence of climate change and also social disruptions. It has been incorporated in global policies as the United Nations Sustainable Development Goals (United Nations, 2016), in global public and private partnerships (ICLEI Local Governments for Sustainability, n.d.; Rockefeller Foundation, n.d.) and can be found as the central topic in multiple heavily funded research-led initiatives that bring together multidisciplinary approaches to resilience (Stanford University, n.d.; University of Warwick, n.d.). The idea of developing more resilient new urban infrastructure and to reinforce the resilience of existing ones is naturally critical for the transport system and for urban mobility in particular, due to its key role on how urban systems work. The implicit consideration of the concept of resilience is not new and many studies that address, for example, energy efficiency in urban transport addressed the ability of mobility systems to become more resilient (Newman and Kenworthy, 2011; Saunders et 
al., 2008; Saunders and da Silva, 2009). Koetse and Rietveld (2009) mentioned the role of having resilient transport infrastructures for all modes for both passenger and freight transport while listing impacts of climate change in the transport system. Fuel crisis, namely linked to the possible oil peak, are also considered as a driver for change in the levels of resilience of transport networks (Krumdieck et al., 2010). However, challenges of measuring long term city resilience are many and are acknowledged by researchers. For example, Leung, Burke and Cui (2017) made this claim explicit when looking at fuel dependence on urban transport. Frameworks have been developed to provide cities and experts with systematic evaluations of resilience, such as the City Resilience Index by ARUP (ARUP, 2014). As we show in the literature review, a myriad of approaches to resilience in transport and mobility have been and are under development. Transport modes and different assessment methods are being evaluated by very sophisticated models to assess resilience. But the literature is absent on considering simple measures of resilience in urban mobility that can be used by the majority of urban and transport planners in contexts of data scarcity and lack of advanced expertise. This is especially important to promote the consideration of resilience in urban mobility planning in small urban areas and in developing countries. Our methodology proposes the use of commonly available origin-destination matrixes to create an aggregate indicator of how resilient an urban mobility system can be in the event of total disruption of the network. We propose an analysis of how many trips done in motorised modes can be transferred to active modes (walking and cycling). We analyse both mode transfer and spatial distribution of trips using a framework that explicitly considers resilience, applying it to two case studies in Brazil.

Our paper is organised as follows: in section 2 we present a literature review that aims at understanding how resilience was incorporated and is conceptualised in transport and mobility studies; in section 3 we present our methodology based on the analysis of origin and destination surveys and a classification of trips according to their level of resilience; in section 4 we present our analysis for two case studies in Brazil, the city of São Carlos in the state of São Paulo and the Metropolitan Region of Maceió, in the state of Alagoas; finally, in section 5 we draw some conclusions from the results and point out future areas of research. 


\section{LITERATURE REVIEW}

\subsection{The concept of resilience}

Urban areas in general, as ecosystems, are increasingly more vulnerable to shocks due to environmental, economical, or social perturbations. These shocks, mixed with the intrinsic complexity of urban areas, put these under permanent adaptation and transformation and make them perfect systems to be perceived under a resilience approach (ARUP, 2014). The authors highlight that a diverse and affordable transport network and an effective transport operation and maintenance are key indicators for resilience in cities. In a more operational perspective, Walker and Cooper (2011) defined resilience as an operational strategy to deal with risk management, a recent approach in finance, urban and environmental management practices. Folke et al. (2010) have introduced the idea of specific resilience when dealing with particular aspects of a system by opposition to general resilience when overall responses to multiple shocks in various parts of the system are addressed. Fernandes et al. (2017) proposed a framework to characterise resilience in urban mobility based on interpretations of the concepts proposed by Folke et al. (2010). Persistent resilience relates to the potential of individuals or groups to keep their mobility patterns without compromising their current quality of life. Adaptable resilience relates to the potential of adopting alternative mobility patterns also without compromising current quality of life levels. Finally, transformable resilience relates to the possibility of transforming current mobility pattern into adaptable and present ones (Fernandes et al., 2017).

\subsection{Resilience in transport}

Chan and Schofer (2016) define resilience in transport sciences as the ability of a transport system to experience a damaging event and return to its common operational state in an admissible amount of time. In a more strategic approach, Leu et al. (2010) stress the ability of a transport system to achieve key strategic objectives when subject to challenges of different nature. Aydin, Duzgun and Heinimann (2017) looked at accessibility to public health facilities as a means to measure resilience in post-disaster contexts. Donovan and Work (2017) used GPS tracking devices on New York taxis and showed evidence of the impact of hurricane Sandy on trip duration. Chan and Schofer (2016) also assessed the resilience of the New York rail transit system due to the hurricanes Irene and Sandy, looking at performance indicators such as revenue vehicle miles and lost service days. The use of technology-based strategies to cope with climate events was proposed for 
developing a resilient mobility system in Ho Chin Minh, Vietnam (ARUP and Siemens, 2015).

Leu, Abbass and Curtis (2010) used GPS measurements to assess the level of resilience of the different transport networks in terms of alternative routes and redundancies. Serulle et al. (2011) measured different performance indicators to integrate them in a decisionmaking system to assess preparedness to an event for the case of Santo Domingo, Dominican Republic. King and Shalaby (2016) applied graph theory to understand the sensitivity of Toronto's transit system to suppression of nodes or links in the system due to shocks. Fotouhi, Moryadee and Miller-Hooks (2017) modelled the impacts of natural and anthropogenic hazard shocks on electric power networks for transit in Minneapolis, USA. Mattioli et al. (2017) developed a method to measure vulnerability to fuel prices considering three main drivers: fuel price, sensitivity to rent and alternative capacity (of non-private car modes). Capri et al. (2016) looked at walking network performance under severe weather using a methodology that assesses accessibility considering the resilience of the network. Stamos et al. (2015) use a mode choice model based on discrete choice theory to assess mode suitability in the event of extreme weather shocks at a panEuropean scale. Krumdieck, Page and Dantas (2010) have modelled the impacts of fuel constraints in mobility in the long term, considering current and future mobility patters. One important proposal in their research is the classification of trips by their level of necessity and by their level of impact. Their proposal regarding necessity includes three classes of trips: optional, necessary and essential (Krumdieck et al., 2010). Levels of impact were classified as low, medium, high and very high impact (Krumdieck et al., 2010).

\section{METHODOLOGY}

The approach developed for the assessment of urban mobility resilience in this study was essentially driven by the following questions:

1. What distances could be travelled by active modes of transport if, for some reason, motorized modes are permanently unavailable?

2. What trips would or would not be affected in that case? Would it be possible to identify groups of trips by looking at their resilience conditions?

3. How would those groups be distributed within the urban region under analysis? 
We have initially defined the concept of Maximum Possible Distances (MPD) and the approach used to measure trip distances between traffic analysis zones (TAZ). We subsequently discussed a strategy to classify resilience by looking at the trip categories following concepts proposed by Fernandes et al. (2017) inspired on the theoretical concepts proposed by Walker et al. (2004) and by Folke et al. (2010). In addition, trips analysed in this study were only those classified by Krumdieck, Page and Dantas (2010) as necessary and essential trips, which are associated to high and very high levels of impact, respectively.

\subsection{The Maximum Possible Distances (MPD)}

Our analysis was based on the assumption that people can walk or cycle up to a certain distance. The concept of Maximum Possible Distance (MPD) was therefore proposed as the theoretical extent that anyone would be willing to walk. The same logic was applied for cycling trips, although these are obviously potentially longer than walking trips. In any case, for the purposes of this study, when we set up a MPD value for walking and another one for cycling, all other trips that go beyond those thresholds would only be possible if made by motorized modes.

The next step of the analysis was the estimation of actual trip distances. This information can be extracted from origin-destination (OD) datasets with the help of geographic information systems (GIS) tools. Centroids of TAZ were used as origins and destinations for all trips beginning or ending within the respective zones. The hypothetical example of Figure 1 shows all possible trips between four zones (A, B, C, and D), which are identified as $\mathrm{AB}, \mathrm{AC}, \mathrm{BC}$, etc. Actual trip distances are then assumed to be the shortest path for each one of those connections (in Figure 1, $d_{A B}, d_{A C}, d_{B C}$, etc.), which can be compared with the walking and cycling MPD adopted in the different scenarios.

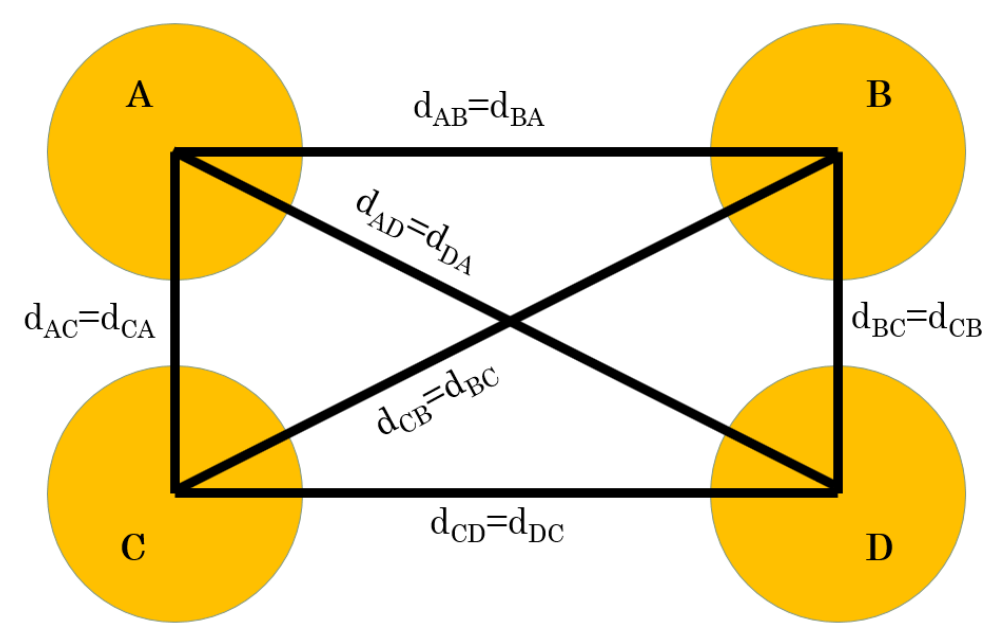


Figure 1 Distance $d_{i j}$ between centroids of traffic analysis zones $i$ and $j(i, j=A, B, C, D)$ of a conceptual city

Finally, if $\mathrm{X}$ is the MPD for walking and $\mathrm{Y}$ is the MPD for cycling, we may observe the following situations:

- $d \leq \mathrm{X}$ - trips can be done by active modes (walking and cycling);

- $\mathrm{X}<d \leq \mathrm{Y}$ - the distance is too long for walking, but not for cycling;

- $\quad d>\mathrm{Y}$ - trips cannot be done by active modes. As a motorized vehicle would be required, trips in that group would be affected in case motorized trips are not possible.

Intrazonal trips, which are usually shorter than the other trips, were assumed to start and end in the same point (i.e. the TAZ centroid). Therefore, trip distances in that case are equal to zero (in Figure $1, \mathrm{~d}_{\mathrm{AA}}=\mathrm{d}_{\mathrm{BB}}=\mathrm{d}_{\mathrm{CC}}=\mathrm{d}_{\mathrm{DD}}=0$ ) and could be counted as walking or cycling trips. We also assumed that trips between any pair of zones have the same distance in both directions (in Figure $1, \mathrm{~d}_{\mathrm{AB}}=\mathrm{d}_{\mathrm{BA}}$ ).

\subsection{Resilience segmentation}

In this step of the process, all trips were classified as persistent, adaptable or transformable. We define persistent trips as those done by active modes within the limits of the respective MPD, i.e. trips on foot for distances shorter than the MPD for walking and trips by bicycle for distances shorter than the MPD for cycling. Adaptable trips are those done by motorized modes within the limits of the MPD, meaning that, if necessary, they can migrate from motorized modes to non-motorized modes. Transformable trips are those done by motorized modes beyond the limits of the MPD. As a consequence, they are too long to be made on non-motorized modes and are considered at risk of not being made due to the external shock. We will refer to them as transformable/at risk.

It is important to keep in mind that the MPD values adopted did not take into account individual characteristics of the travellers (e.g. age) or of the terrain (e.g. slope). As a consequence, we may find travellers who actually use active modes for trips that are longer than the respective MPD values for walking and cycling. We classified these as a different group of trips, named exceptional trips. Exceptional trips, along with persistent and adaptable trips, are considered resilient trips, as summarized in Figure 2. The resilience level of a city or region is therefore given by the relative number of persistent, 
adaptable and exceptional trips (according to Table 1). Transformable/at risk trips, on the other hand, represent the vulnerability level of the system.

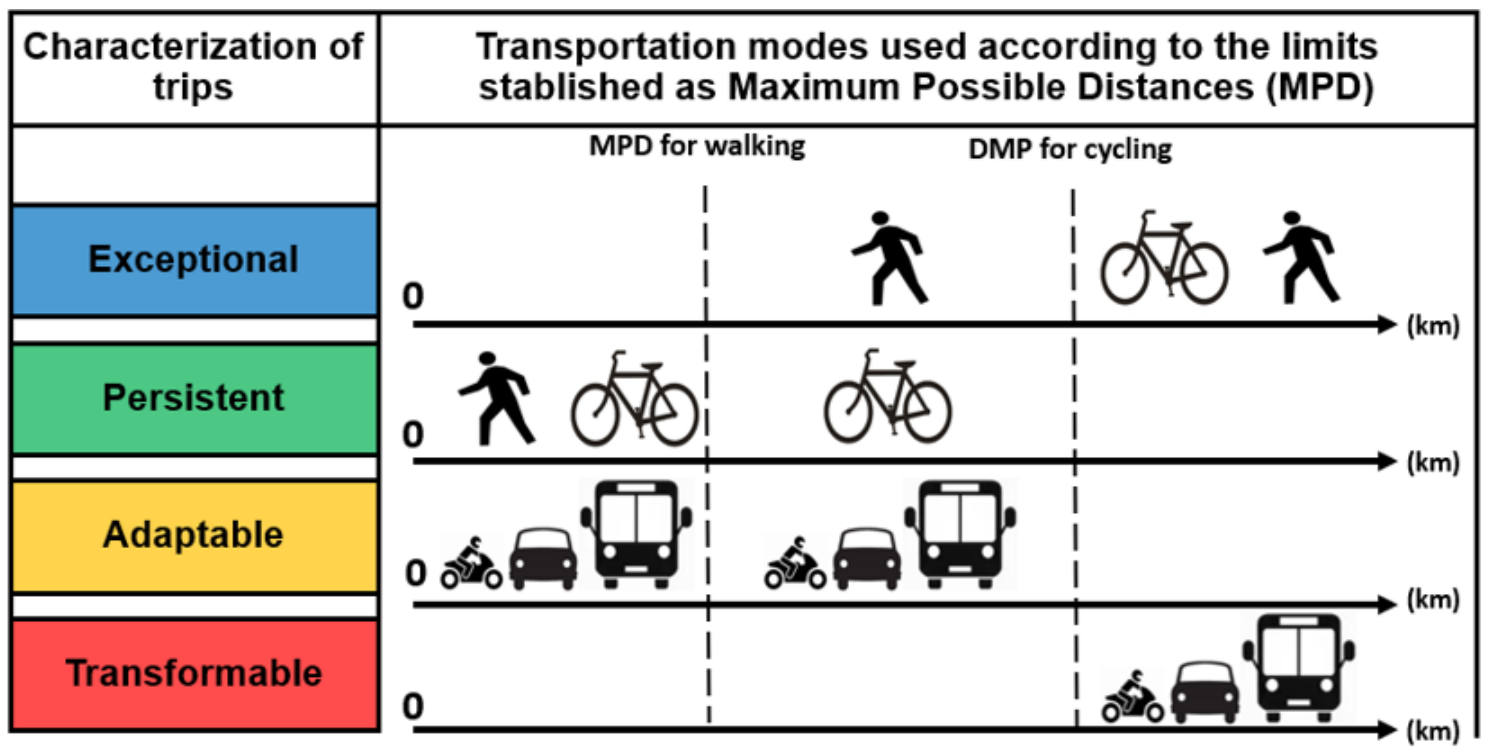

Figure 2 Graphic legend for characterising trips (exceptional, persistent, adaptable and transformable/at risk) according to the transport mode used within MPD for walking and bicycle (authors' own)

Table 1 Level of resilience

\begin{tabular}{cccccc}
\hline Resilience level & Very Low & Low & Medium & High & Very High \\
\hline $\begin{array}{c}\text { Resilient Trips } \\
(\%)\end{array}$ & $0-20.0$ & $20.1-40.0$ & $40.1-60.0$ & $60.1-80.0$ & $80.1-100$ \\
\hline
\end{tabular}

\subsection{Resilience variation and distribution by zone}

The influence of MPD values on resilience levels was analysed through the various scenarios built with different predefined MPD values. The distribution of persistent, adaptable, transformable/at risk and exceptional trips by TAZ was also investigated. The outcome of this type of analysis may be particularly useful to urban planning at a strategic level. 


\section{RESULTS AND DISCUSSION}

\subsection{The case studies}

We used two case studies in Brazil, the city of São Carlos in the state of São Paulo and the Metropolitan Region of Maceió (MRM), in the state of Alagoas.

São Carlos is a mid-size Brazilian university city with an estimated population of 246 thousand inhabitants in 2017 (Instituto Brasileiro de Geografia e Estatística, 2010) which hosts two campuses of the main São Paulo public universities, with a significant concentration of qualified jobs in both the manufacturing and service sectors. In the case of São Carlos, the data used refers to the Origin-Destination (OD) survey of 2007/2008 made in 41 traffic analysis zones (TAZ), as depicted in Figure 3, accounting for 6821 daily trips, with a breakdown of 2871 trips in private vehicle, 1445 on bus, 2883 by walking and 222 by bicycle. Maceió is the state capital of Alagoas, a larger urban conurbation (in comparison with São Carlos) with an estimated population of 1,12 million inhabitants in 2017 (Instituto Brasileiro de Geografia e Estatística, 2010). This metropolitan area hosts a series of state services and branches of central government agencies that work as additional attractors to the local economy based on mineral extraction and manufacturing sectors. In the case of the MRM, which includes the municipalities of Maceió, Rio Largo and Satuba, the OD survey used was made in 2014. It refers to $83 \mathrm{TAZ}$ as depicted in Figure 4, accounting to a total of 6038 daily trips, with 1917 by private vehicles, 1764 on bus, 2080 by walking and 277 by bicycle. The total number of daily trips in MRM is lower than expected when compared with the same value for São Carlos, considering the relative size of both urban areas. This is the result of different methodologies for the two case studies that were accepted as correct.

Figure 5 depicts the frequency distribution of trips per distance. In São Carlos, 73.1 percent of trips had itineraries shorter or equal to 4 kilometres, while in MRM the value drops to 60.3 percent (with 97.6 percent of trips for São Carlos and 81.3 percent of trip for MRM for trips under 8 kilometres). These values indicate the high potential of use of active modes in both urban areas. 


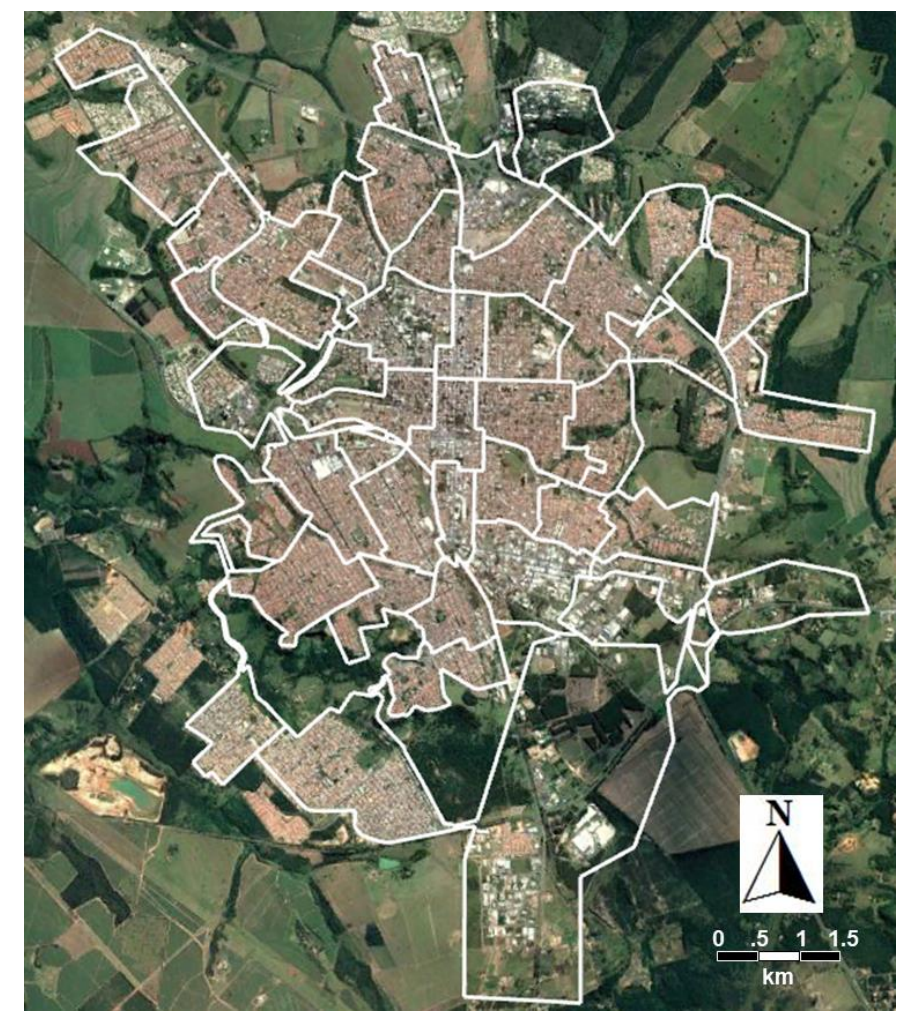

Figure 3 TAZ in the city of São Carlos, background Google Earth (authors' own)

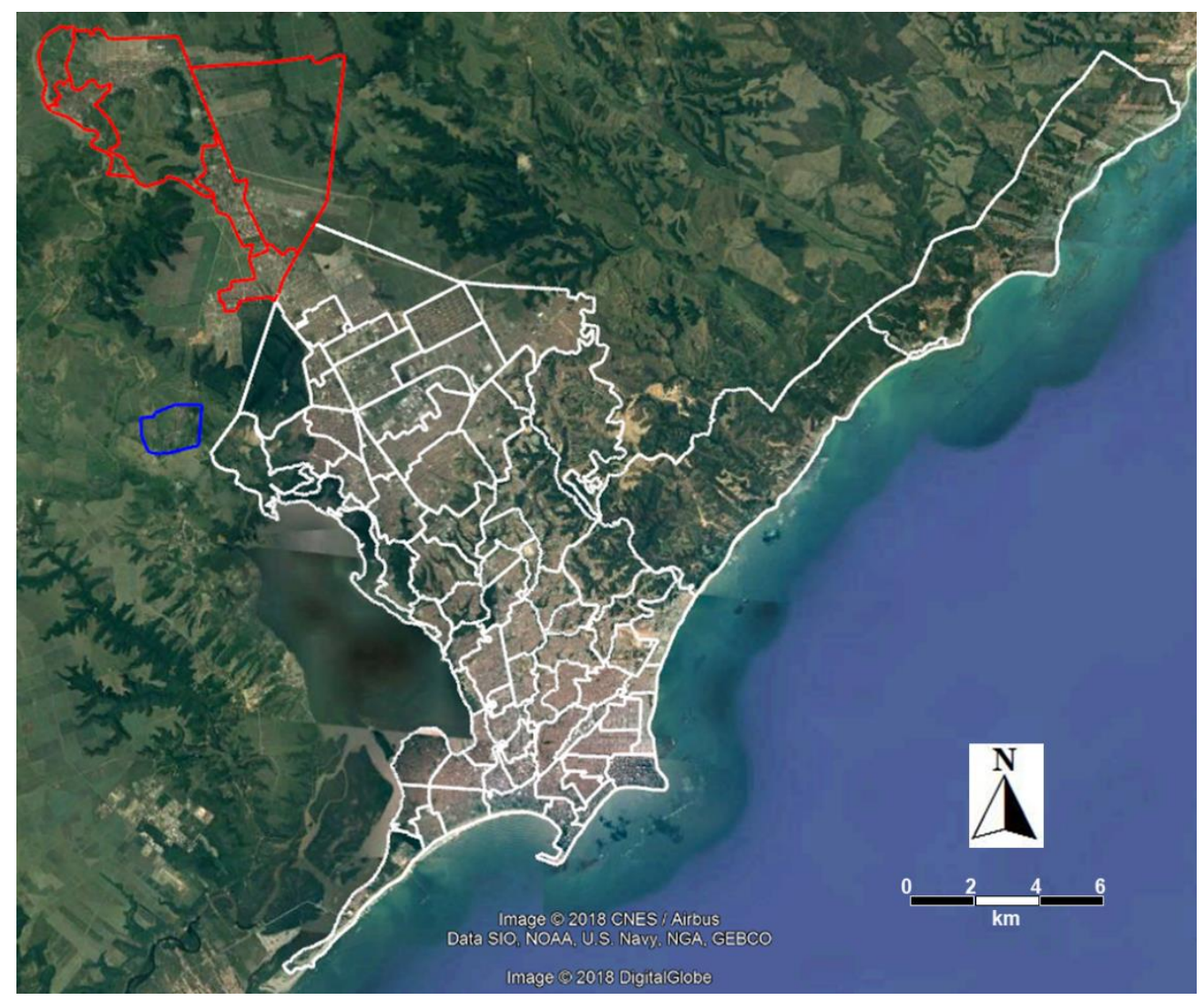

Figure 4 TAZ in the Metropolitan Region of Maceió: Municipalities of Maceió (white), Satuba (blue) and Rio Largo (red), background Google Earth (authors' own) 


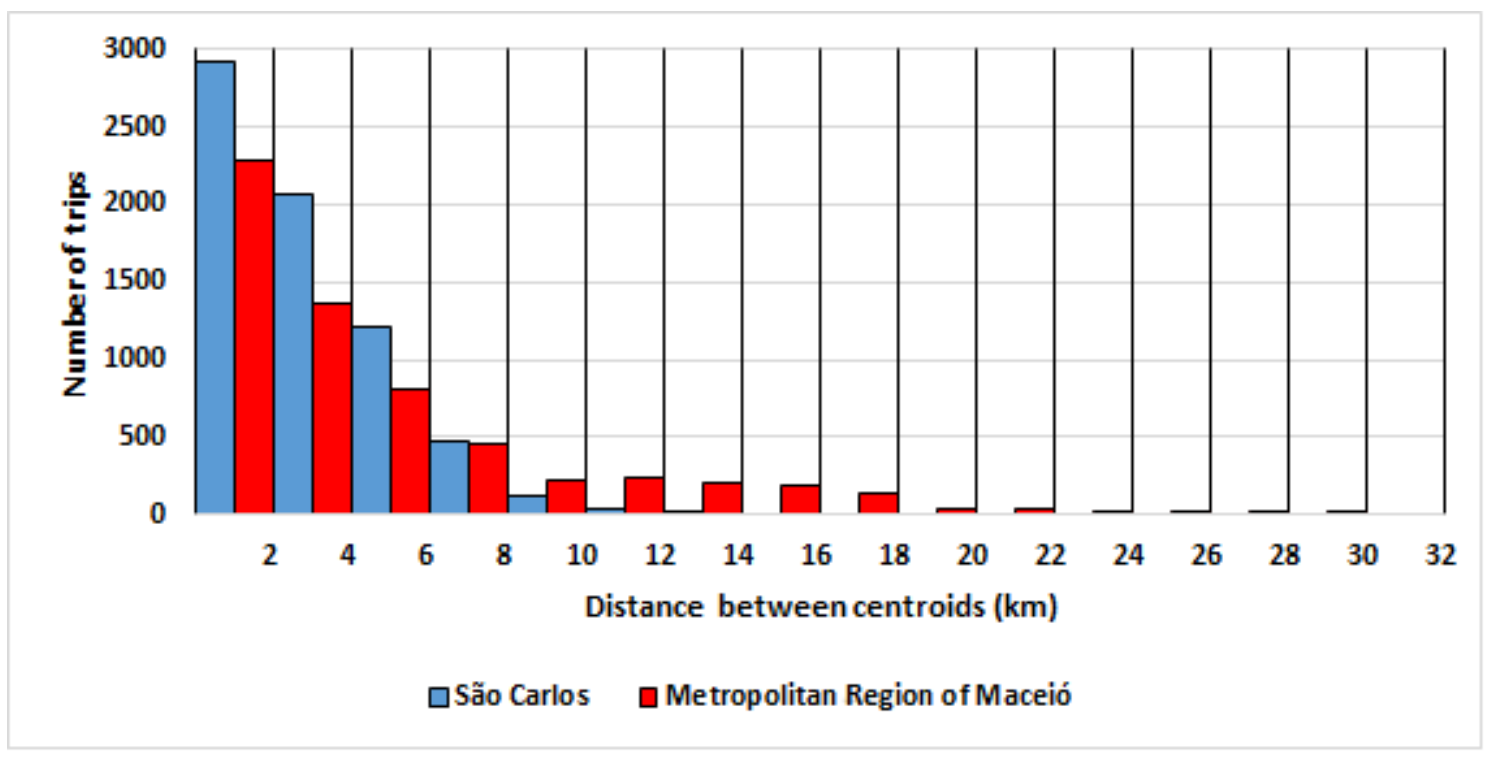

Figure 5 Distribution of trips per distance between centroids of TAZ for São Carlos (2007/2008) and for the Metropolitan Region of Maceió (2014) (authors' own)

\subsection{The values of Maximum Possible Distance}

The definition of the values of MPD for each mode takes into consideration influencing factors such as age, physical/health condition, along with terrain using the street gradients. In order to identify the value of MPD for both walking and cycling modes, we opted to vary the value of MPD in multiple scenarios of increasing MPD, starting with a minimal distance of 0 kilometres which corresponds to intrazonal trips done on active modes and ending with the MPD value that would correspond to 100 percent of trips done only on active modes. Table 2 lists all the 89 scenarios tested for São Carlos and 259 scenarios tested for MRM considering the variation of MPD values for both walking and cycling modes.

Table 2 List of 89 scenarios tested for São Carlos and 259 scenarios tested for MRM

\begin{tabular}{cccccccccc}
\hline & \multicolumn{7}{c}{ MPD for walking mode (km) } \\
\hline $\begin{array}{c}\text { MPD for } \\
\text { cycling mode } \\
(\mathbf{k m})\end{array}$ & 0 & 0.5 & 1.0 & 1.5 & 2.0 & 2.5 & 3.0 & 3.5 & 4.0 \\
\hline 0 & 1 & - & - & - & - & - & - & - & - \\
\hline 0.5 & - & 2 & - & - & - & - & - & - & - \\
\hline 1.0 & - & - & 3 & - & - & - & - & - & - \\
\hline 1.5 & - & - & - & 4 & - & - & - & - & - \\
\hline 2.0 & - & - & - & - & 5 & - & - & - & - \\
\hline 2.5 & - & - & - & - & 6 & 7 & - & - & - \\
\hline 3.0 & - & - & - & - & 8 & 9 & 10 & - & - \\
\hline 3.5 & - & - & - & - & 11 & 12 & 13 & 14 & - \\
\hline 4.0 & - & - & - & - & 15 & 16 & 17 & 18 & 19 \\
\hline 4.5 & - & - & - & - & 20 & 21 & 22 & 23 & 24 \\
\hline
\end{tabular}




\begin{tabular}{|c|c|c|c|c|c|c|c|c|c|}
\hline 11.0 & - & - & - & - & 85 & 86 & 87 & 88 & $89 *$ \\
\hline 11.5 & - & - & - & - & 90 & 91 & 92 & 93 & 94 \\
\hline \multicolumn{10}{|c|}{$\ldots$} \\
\hline 28.0 & - & - & - & - & 255 & 256 & 257 & 258 & 259 \\
\hline
\end{tabular}

* Last scenario tested for São Carlos

It was also assumed that the MPD for walking is shorter or equal to the MPD for cycling. For all scenarios with MPD on walking above 4.0 kilometres we considered, for each MPD on bicycle, five scenarios for MPD on walking mode, varying from 2 to 4 kilometres with increments of 500 metres. The value of MPD on cycling was also incremented of 500 metres on each scenario.

A sample of values for resilience for each scenario is listed in Table 3. São Carlos reached a maximum value of MPD for cycling of 11 kilometres when 100 percent of trips can be transferred to active modes (thus being resilient), having started with 40.4 percent of resilient trips at zero distance. The MRM reached a maximum value of MPD for cycling of 28 kilometres when 100 percent of trips can be transferred to active modes, having started with 43.0 percent of resilient trips at zero distance. The significant difference in the overall maximum value for the MPD for cycling is an obvious consequence of the difference of urban scales between MRM and São Carlos urban areas.

Table 3 Examples of resilience values per scenario in São Carlos and Metropolitan Region of Maceió 


\begin{tabular}{|c|c|c|c|c|c|c|c|}
\hline \multicolumn{4}{|c|}{ São Carlos } & \multicolumn{4}{|c|}{ Metro Region of Maceió } \\
\hline \multirow{2}{*}{ Scenario } & \multicolumn{2}{|c|}{ MPD $(\mathrm{km})$} & \multirow{2}{*}{$\begin{array}{c}\text { Resilience } \\
(\%)\end{array}$} & \multirow{2}{*}{ Scenario } & \multicolumn{2}{|c|}{ MPD $(\mathrm{km})$} & \multirow{2}{*}{$\begin{array}{c}\text { Resilience } \\
(\%)\end{array}$} \\
\hline & Walking & Bicycle & & & Walking & Bicycle & \\
\hline 1 & 0 & 0 & 40.4 & 1 & 0 & 0 & 43.0 \\
\hline 2 & 0.5 & 0.5 & 40.4 & 2 & 0.5 & 0.5 & 43.0 \\
\hline 3 & 1 & 1 & 41.5 & 3 & 1 & 1 & 43.2 \\
\hline 4 & 1.5 & 1.5 & 47.0 & 4 & 1.5 & 1.5 & 44.6 \\
\hline 5 & 2 & 2 & 52.1 & 5 & 2 & 2 & 47.0 \\
\hline 6 & 2 & 2.5 & 57.3 & 6 & 2 & 2.5 & 51.6 \\
\hline 7 & 2.5 & 2.5 & 57.3 & 7 & 2.5 & 2.5 & 51.6 \\
\hline 8 & 2 & 3 & 63.8 & 8 & 2 & 3 & 54.4 \\
\hline 9 & 2.5 & 3 & 63.8 & 9 & 2.5 & 3 & 54.4 \\
\hline 10 & 3 & 3 & 63.8 & 10 & 3 & 3 & 54.4 \\
\hline 11 & 2 & 3.5 & 71.3 & 11 & 2 & 3.5 & 58.5 \\
\hline 12 & 2.5 & 3.5 & 71.3 & 12 & 2.5 & 3.5 & 58.5 \\
\hline 13 & 3 & 3.5 & 71.3 & 13 & 3 & 3.5 & 58.5 \\
\hline 14 & 3.5 & 3.5 & 71.3 & 14 & 3.5 & 3.5 & 58.5 \\
\hline 15 & 2 & 4 & 75.9 & 15 & 2 & 4 & 62.5 \\
\hline 16 & 2.5 & 4 & 75.9 & 16 & 2.5 & 4 & 62.5 \\
\hline 17 & 3 & 4 & 75.9 & 17 & 3 & 4 & 62.5 \\
\hline 18 & 3.5 & 4 & 75.9 & 18 & 3.5 & 4 & 62.5 \\
\hline 19 & 4 & 4 & 75.9 & 19 & 4 & 4 & 62.5 \\
\hline \multicolumn{4}{|c|}{$\ldots$} & \multicolumn{4}{|c|}{$\ldots$} \\
\hline 80 & 2 & 10.5 & 99.8 & 250 & 2 & 10.5 & 99.9 \\
\hline 81 & 2.5 & 10.5 & 99.8 & 251 & 2.5 & 10.5 & 99.9 \\
\hline 82 & 3 & 10.5 & 99.8 & 252 & 3 & 10.5 & 99.9 \\
\hline 83 & 3.5 & 10.5 & 99.8 & 253 & 3.5 & 10.5 & 99.9 \\
\hline 84 & 4 & 10.5 & 99.8 & 254 & 4 & 10.5 & 99.9 \\
\hline 85 & 2 & 11 & 100 & 255 & 2 & 28.0 & 100 \\
\hline 86 & 2.5 & 11 & 100 & 256 & 2.5 & 28.0 & 100 \\
\hline 87 & 3 & 11 & 100 & 257 & 3 & 28.0 & 100 \\
\hline 88 & 3.5 & 11 & 100 & 258 & 3.5 & 28.0 & 100 \\
\hline 89 & 4 & 11 & 100 & 259 & 4 & 28.0 & 100 \\
\hline
\end{tabular}

\subsection{Segmentation of trips and level of resilience}

Figure 6 depicts the variation of the resilience level with the variation of the MPD for cycling. It is possible to observe in Figure 6 structured patterns of trip mode migration to active modes in both São Carlos and the MRM according to the MPD values for cycling. 


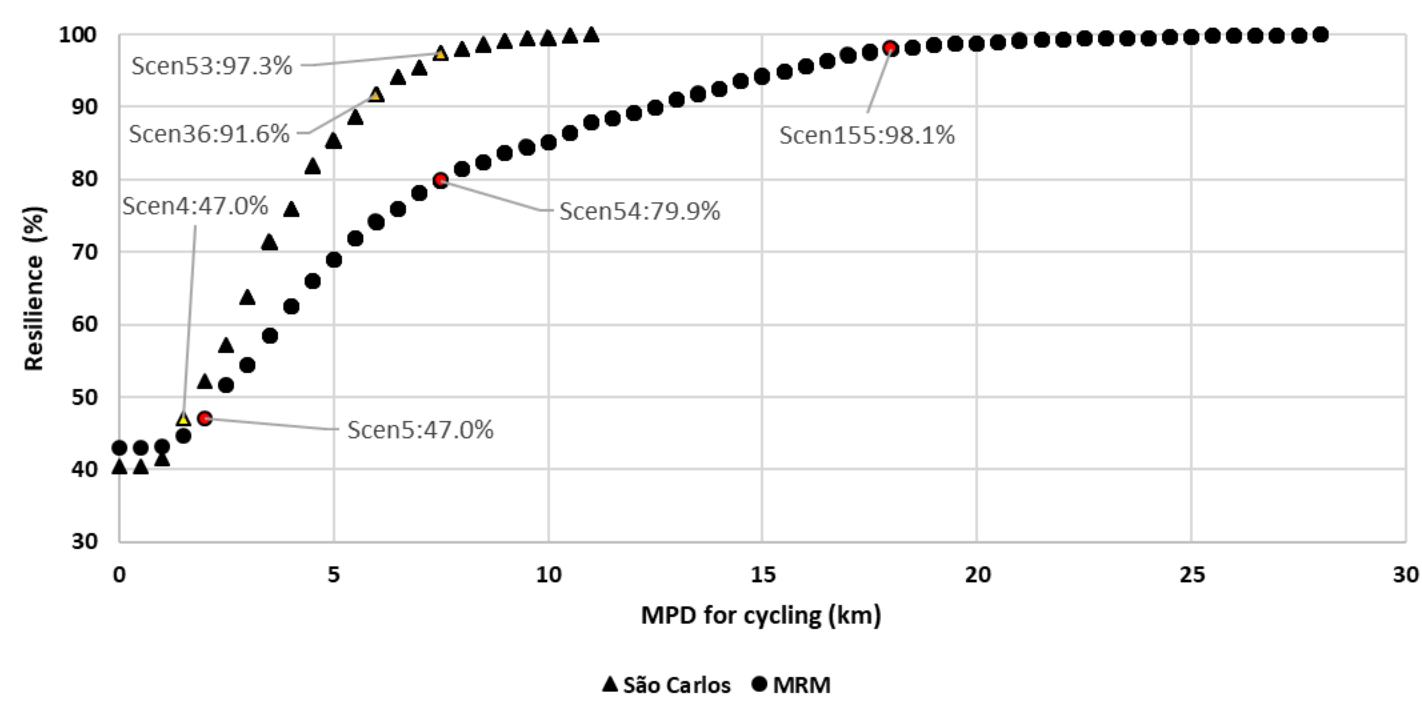

Figure 6 Variation of resilience in São Carlos and Metropolitan Region of Maceió for different values of MPD for bicycle (authors' own)

The first variation of resilience refers to trips with a 0 kilometre distance, corresponding to scenarios 1 for both case studies. São Carlos has a value of 40.4 percent, which corresponds to 18.2 percent of intrazonal trips plus 22.2 percent for trips classified as exceptional (long distance trips captives of the active modes). The MRM has a value of 43.0 percent, 27.4 percent for intrazonal trips and 15.6 percent for exceptional trips. Although the total value is similar, the MRM shows a bigger importance of intrazonal trips, most probably a consequence of its natural context of state capital city, with local accessibility being more important in the daily life.

The first big gain in mode transfer to active modes (and thus increased resilience) occur in scenario 4 for São Carlos (MPD of 1.5 kilometres for both walking and cycling), in which 13.6 percent of exceptional trips, 23.2 percent of persistent trips and 10.2 percent of adaptable trips become possible in active modes, with an overall increase of the resilience to 47.0 percent. In the MRM, this change happens in scenario 5 (MPD of 2.0 kilometres for both walking and cycling), with 9.7 percent of exceptional trips, 29.3 percent of persistent trips and 8.0 percent of adaptable trips becoming possible in active modes, with an overall increase of the resilience to 47.0 percent. These values mark the start of a new, quicker trend of gain in resilience for both São Carlos and the MRM.

This trend starts to slow down in scenario 36 for São Carlos (MPD of 2.5 kilometres for walking and 6.0 for cycling), when 5.0 percent of exceptional trips, 31.7 percent of persistent trips and 54.9 percent of adaptable trips become possible in active modes, with an overall increase of the resilience to 91.6 percent. In São Carlos the rate of mode transfer 
peaks around scenario 53 (MPD of 3.5 kilometres for walking and 7.5 for cycling) when 2.6 percent of exceptional trips, 34.2 percent of persistent trips and 60.6 percent of adaptable trips become possible in active modes, with an overall increase of the resilience to 97.3 percent, to finally converge to 100 percent with little resilience gains in scenario 89 with an MPD of 11 kilometres for cycling.

In the MRM, the trend is slightly different. A new rate of change starts around scenario 52 (MPD of 3.0 kilometres for walking and 7.5 for cycling), with 2.7 percent of exceptional trips, 36.3 percent of persistent trips and 40.8 percent of adaptable trips becoming possible in active modes, with an overall increase of the resilience to 79.9 percent. It ends around scenario 155 (MPD of 2.0 kilometres for walking and 18.0 for cycling), with 7.0 percent of exceptional trips, 32.0 persistent trips and 59.0 percent of adaptable trips becoming possible in active modes, with an overall increase of the resilience to 98.1 percent. After this point, no significant gains in resilience are observed, ending in scenario 259 with an MPD of 28 kilometres.

The fastest rate of change in São Carlos is most probably a consequence of a mix of factors including a much warmer climate in MRM, a less important share of motorized vehicles and a more spread distribution of the local trip generators. These values show that achieving higher levels of resilience in larger transport systems such as the one of the MRM is more difficult due to the longer distances where the active modes, even cycling, are not as attractive.

\subsection{Spatial distribution of trips per TAZ}

We have mapped the spatial distribution of trips along the TAZs to identify local trends or possible patterns of potential to increase resilience. We have only plotted the maps for some selected scenarios that illustrate the main thresholds of gains in resilience as discussed in the previous section.

As expected and observable in Figure 7, in São Carlos transformable/at risk trips were located in peripheral areas of the city; the persistent and adaptable trips were located in central areas where walking and, to a very small extent, cycling are already preferred modes. The city centre is more prone to mode shit for shorter values of MPD, as seen in Figure 7 (b), while transformable/at risk trips are more resistant to change in the most peripheral zones (as expected) particularly in the more populated southern TAZ. 

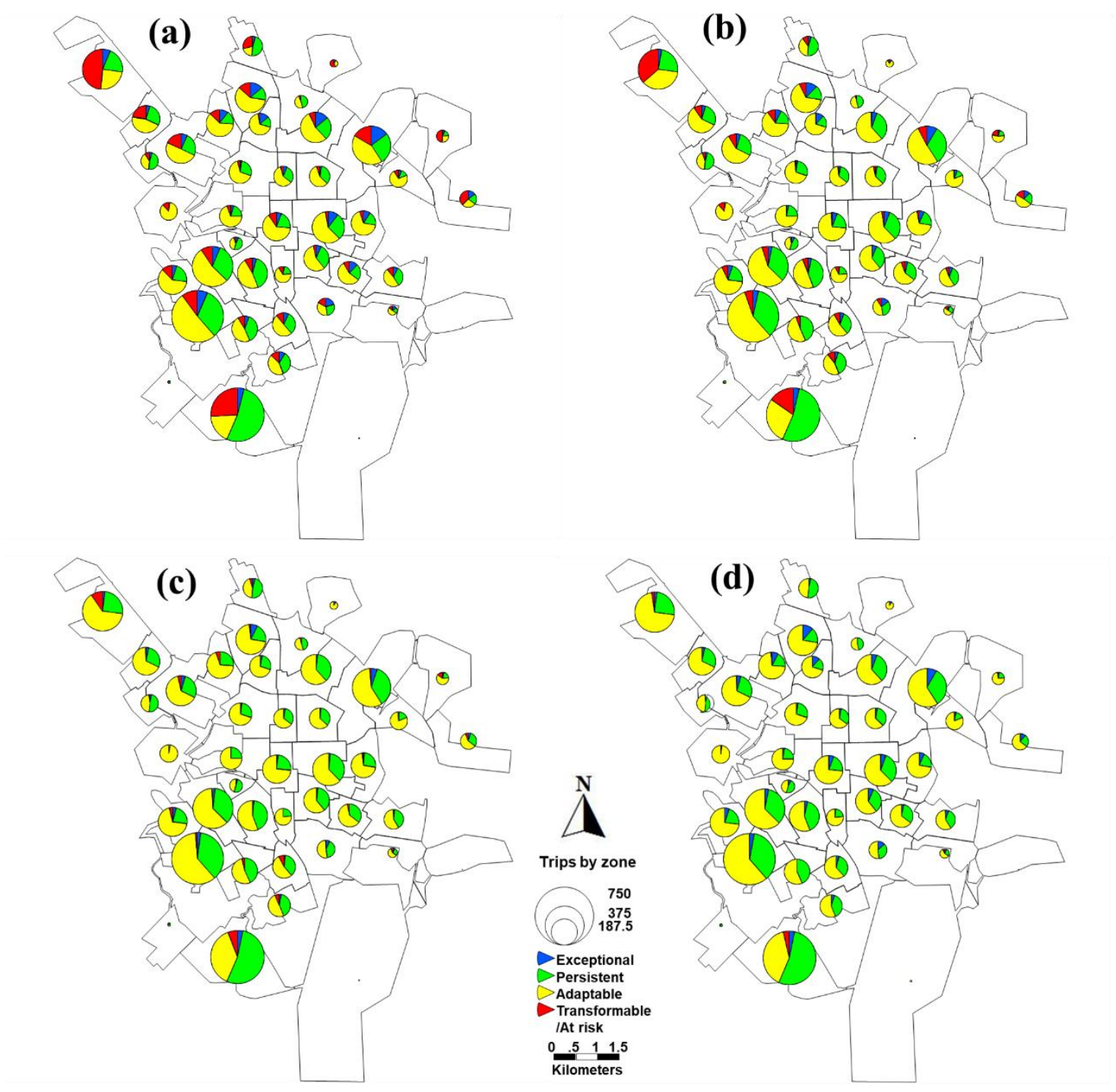

Figure 7 Spatial distribution of resilience per TAZ in São Carlos for a sample of scenarios: (a) Scenario 18: MPD walking $=3.5 \mathrm{~km}$ and MPD bicycle $=4.0 \mathrm{~km}$, (b) Scenario 36: MPD walking $=2.5 \mathrm{~km}$ e MPD bicycle $=6.0 \mathrm{~km}$, (c) Scenario 53: MPD walking $=3.5 \mathrm{~km}$ e MPD bicycle $=7.5 \mathrm{~km}$ e (d) Scenario 71: MPD walking = $2.5 \mathrm{~km}$ e MPD bicycle $=9.5 \mathrm{~km}$ (authors' own)

In the MRM, the spatial distribution of trips depicted in Figure 8 shows that transformable/at risk trips are consistently located in the upper, northern town, and also along the eastern coastal TAZ, all of which have lower levels of accessibility. Transformable trips are also a significant share of the trips in more central TAZ for lower values of MPD (Figure 8 (a) and (b)). As we increased the values of MPD, the share of transformable/at risk trips in the eastern coastal TAZ is higher than in the northern ones, although with much smaller absolute number of trips. 


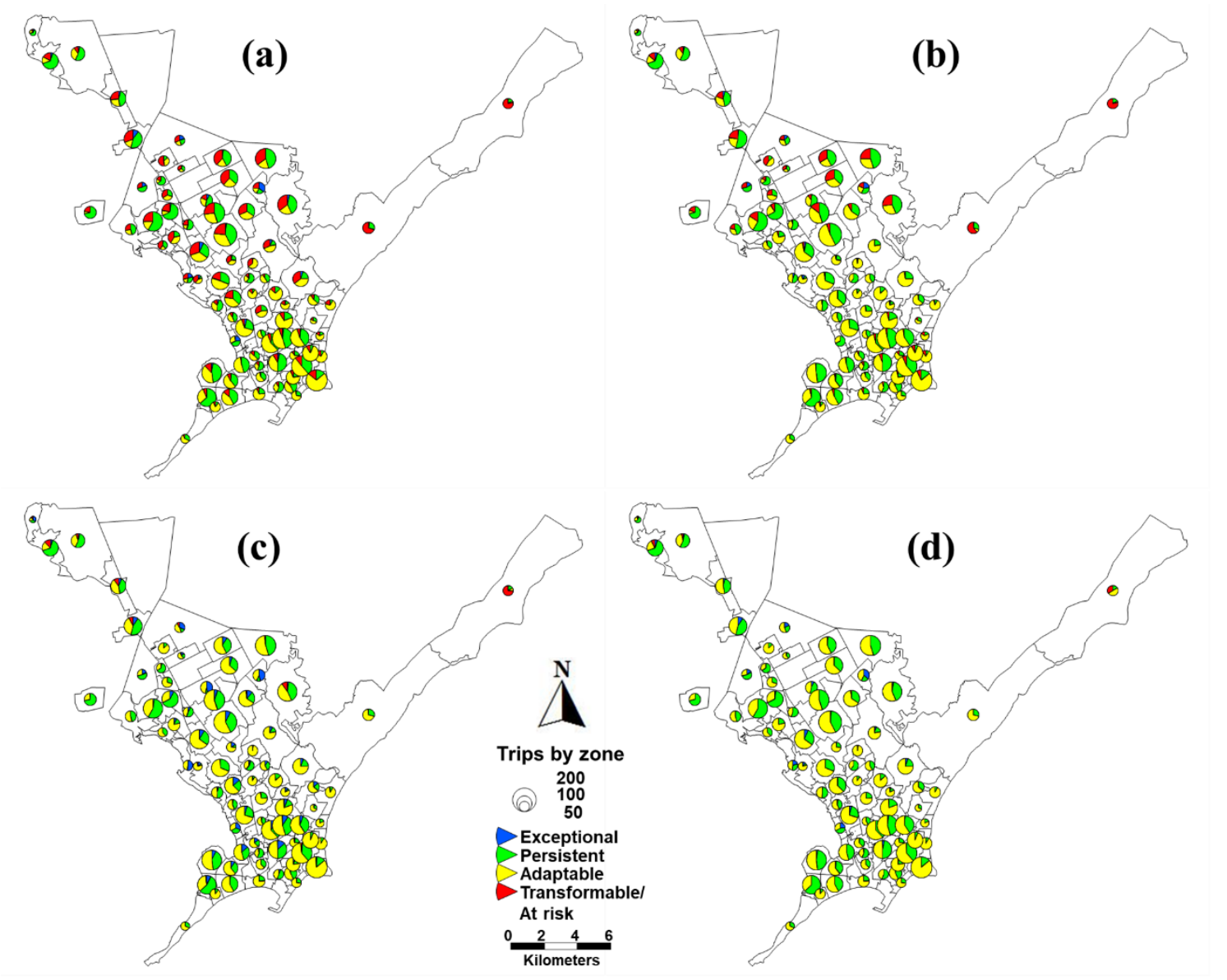

Figure 8 Spatial distribution of resilience per TAZ in the Metropolitan Region of Maceió for a sample of scenarios: (a) Scenario 52: MPD walking $=3.0 \mathrm{~km}$ e MPD bicycle $=7.5 \mathrm{~km}$, (b) Scenario 104: MPD walking $=4.0 \mathrm{~km}$ e MPD bicycle $=12.5 \mathrm{~km}$, (c) Scenario 155: MPD walking $=2.0 \mathrm{~km}$ e MPD bicycle $=18.0 \mathrm{~km}$ e (d) Scenario 207: MPD walking $=3.0 \mathrm{~km}$ e $\mathrm{MPD}$ bicycle $=23.0 \mathrm{~km}$ (authors' own)

\subsection{Impacts of resilience by level of income}

Results also allow an analysis of the impact of the increase of resilience in trips considering individual or household characteristics, such as income. Figure 9 depicts the classification of trips per distance travelled (in kilometres) and average individual monthly income (in Brazilian Reais, BRL) for the scenarios highlighted in Figure 6 and considering the four classes of resilience (as described in Figure 2). Income data was obtained in the OD surveys for both São Carlos and the MRM. Trips that have a zero value for income may represent incomplete survey entries or unemployed individuals and were considered as they have been used to classify resilience. The difference in the range of individual monthly income between São Carlos (max BRL 10,000) and the MRM (max around BRL 36,000) is possibly related to the existence of more top paid salaries in the MRM as a state capital. 
A first finding shows a tendency among more affluent individuals (with individual monthly income above BRL 2000 in São Carlos and BRL 3000 in the MRM) to do mainly Adaptable and Transformable trips (dependent on motorised modes) both in lower and higher levels of resilience.
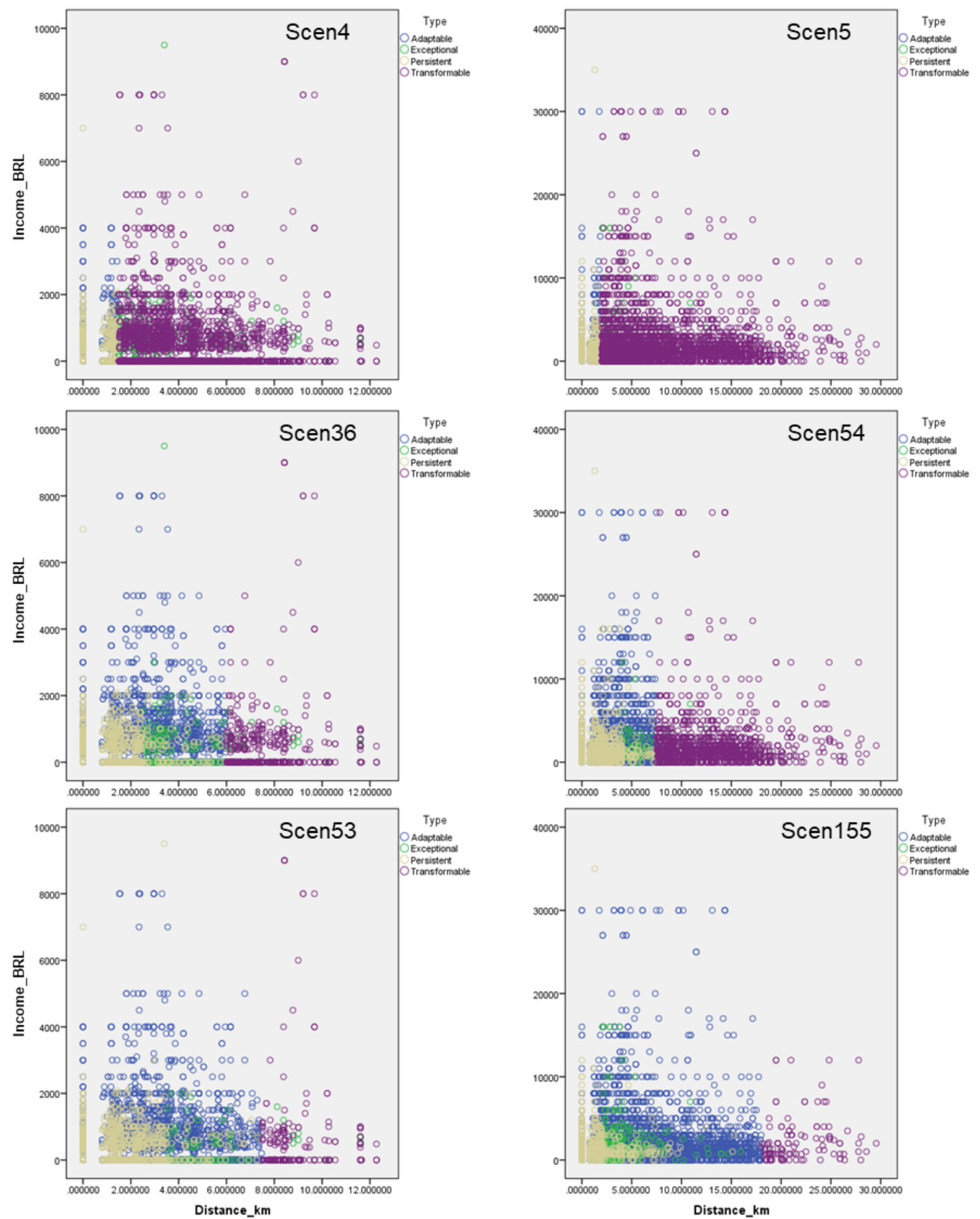

(a) São Carlos

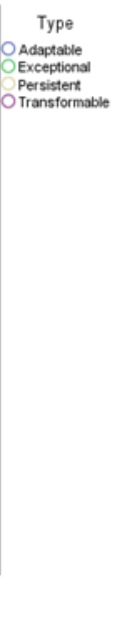

(b) MRM

Figure 9 Relationship between distance of trip and average monthly individual income (in Brazilian Reais, BRL) for (a) São Carlos and (b) the Metropolitan Region of Maceió. Each graphic correspond to a key scenario indicated in Figure 6. 
The impact of the variation of resilience by income levels is similar in both cases, where Transformable trips dominate from the early stages (scenario 4 in Figure 9(a) and 5 in Figure 9(b)) to become residual in the last stage of the variation of resilience with a much less dense cloud of points (scenario 53 in Figure 9(a) and 155 in Figure 9(b)). This is particularly important as, in both cases, the large number of trips that have more gains in resilience (trips moving from Transformable to Persistent) are done mostly by less affluent individuals (with individual monthly income below BRL 2000 in São Carlos and BRL 3000 in the MRM). However, the relative importance of Adaptable (motorised) trips among the less affluent individuals is still very high, as it is seen in Figure 9(a) for São Carlos in scenario 53, showing the potential for implementing policy measures to make them more resilient.

Figure 9 also shows for both case studies that the very long trips (longer than approximately 7 kilometres for São Carlos and longer than approximately 18 kilometres for the MRM) are done mainly by low income individuals, a cohort that is much more vulnerable to the impacts of shocks.

\section{CONCLUSIONS}

Our research aimed at analysing a classification of urban commuting trips from a resilience standpoint considering the possibility of changing the modes based on combustion engine vehicles to what is commonly known as active modes in case a given shock (of different natures, e.g. due to peaks in fuel prices or extreme weather events) would create disruptions to an urban mobility system. We have drawn on previous research on characterising resilience by Folke et al. (2010) and have expanded the concept to include all trips that are made in all urban transport modes to look on how a traditional OD survey, which is a common and widely used transport planning tool, can be used to give an overall idea of how resilient mobility is in different spatial contexts. Two case studies in Brazil were used, São Carlos, a mid-size city in the state of São Paulo that has a high economic and socio-demographic profile, and the Metropolitan Region of Maceió, the capital of the state of Alagoas with a much larger (but not better served) transport system.

Our methodology is based on the simple concept of mode transfer (due to the shock) as a function of distance thresholds for the resilient modes. We believe this is a good indicator as for where to address problems in the event of a shock, in order to maximize the number 
of trips that still provide high levels of accessibility to the population. The assumption that active modes could be chosen even if travel distances are significant comes from the hypothesis that, in the event of a shock with deep impact on the system, trips still need to be done. The simplicity of the methodology has great potential to be applied in decision making processes in transport planning especially in contexts where data availability and expertise do not allow the application of more sophisticated methods. OD itineraries and trips were compared with a systematic variation of the maximum possible distances (MPD) for the active modes to identify which pairs OD could be more resilient, i.e. could hold more mode transfer from motorised to active modes.

The sensitivity analysis of the scenarios showed two main distance thresholds that represent significant changes in the level of resilience. The first one, of around 2 kilometres for both São Carlos and the MRM, marks the point until which no gains in resilience are achieved as all trips are mainly captive of the two active modes. After this point, mode change and thus resilience increases significantly, especially in São Carlos, despite the increasing values of distance. The second distance threshold corresponds to the moment in which no more significant gains can be obtained, due to the very long travel distances. This happens in São Carlos at around 6.0 kilometres (approximately 90 percent of the trips could be on active modes, thus resilient) while for the MRM there are two points, 7.5 kilometres (but a lower level of resilience of around 80 percent) and at around 18.0 kilometres (at which almost all trips could be transferred to active modes), showing evidence of the importance of longer trips due to the metropolitan nature of the MRM.

The methodology showed potential for cross-analyses between the classification of resilience and socioeconomic indicators. The analysis of income levels and trip distances showed different sensitivity to resilience levels between less and more affluent individuals and different levels of dependence of motorised modes and vulnerability to risks.

The work presented in this paper reports the first stage of a larger research project that aims at analysing resilience in urban mobility as a way to ensure a more equitable use of the transport system in case of severe disruptions. The main aim of this long term research is to develop a decision support package to be used in low-data and low-expertise contexts where mobility planners and agencies need to assess and plan for resilience in their own geographical contexts, for example small local authorities in developing countries. We 
are considering disaggregated indicators for different transport modes with specific methodological approaches that allow highlight resilience patterns per mode. We are also working on incorporating measures of inequality linked to accessibility which can be used as an operational tool to deal with events while ensuring a fairer use of the transport system.

\section{ACKNOWLEDGMENTS}

Acknowledgments are not included for blind review.

\section{REFERENCES}

ARUP, 2014. City Resilience Index.

ARUP and Siemens, 2015. Resilient Urban Mobility a case study of integrated transport in Ho Chi Minh City - Arup.

Aydin, N.Y., Duzgun, S., Heinimann, H., 2017. Resilience evaluation for transportation networks accessibility under seismic risk, in: CUPUM Conference on Compueters in Urban Planning and Urban Management.

Caprì, S., Ignaccolo, M., Inturri, G., Le Pira, M., 2016. Green walking networks for climate change adaptation. Transp. Res. Part D Transp. Environ. 45, 84-95. https://doi.org/10.1016/j.trd.2015.08.005

Chan, R., Schofer, J.L., 2016. Measuring Transportation System Resilience: Response of Rail Transit to Weather Disruptions. Nat. Hazards Rev. 17, 05015004. https://doi.org/10.1061/(ASCE)NH.1527-6996.0000200

Donovan, B., Work, D.B., 2017. Empirically quantifying city-scale transportation system resilience to extreme events. Transp. Res. Part C 79, 333-346. https://doi.org/10.1016/j.trc.2017.03.002

Fernandes, V.A., Rothfuss, R., Hochschild, V., Da Silva, W.R., Santos, M.P. de S., 2017. Resiliência da mobilidade urbana: uma proposta conceitual e de sistematização. Transportes 25, 147. https://doi.org/10.14295/transportes.v25i4.1079

Folke, C., Carpenter, S.R., Walker, B., Scheffer, M., Chapin, T., Rockström, J., 2010. Resilience thinking: Integrating resilience, adaptability and transformability. Ecol. 
Soc. 15. https://doi.org/10.5751/ES-03610-150420

Fotouhi, H., Moryadee, S., Miller-Hooks, E., 2017. Quantifying the resilience of an urban traffic-electric power coupled system. Reliab. Eng. Syst. Saf. 163, 79-94. https://doi.org/10.1016/j.ress.2017.01.026

Holling, C.S., 1973. Resilience and Stability of Ecological Systems. Annu. Rev. Ecol. Syst. 4, 1-23. https://doi.org/10.1146/annurev.es.04.110173.000245

ICLEI Local Governments for Sustainability, n.d. Resilient Cities [WWW Document]. URL http://resilient-cities.iclei.org/ (accessed 8.17.18).

Instituto Brasileiro de Geografia e Estatística, 2010. Cidades IBGE [WWW Document]. URL https://cidades.ibge.gov.br/brasil/sp/sao-carlos/panorama (accessed 8.14.18).

King, D., Shalaby, A., 2016. Performance Metrics and Analysis of Transit Network Resilience in Toronto, in: TRB 95th Annual Meeting Compendium of Papers. Washington, D.C.

Koetse, M.J., Rietveld, P., 2009. The impact of climate change and weather on transport: An overview of empirical findings. Transp. Res. Part D Transp. Environ. 14, 205221. https://doi.org/10.1016/j.trd.2008.12.004

Krumdieck, S., Page, S., Dantas, A., 2010. Urban form and long-term fuel supply decline: A method to investigate the peak oil risks to essential activities. Transp. Res. Part A Policy Pract. 44, 306-322. https://doi.org/10.1016/j.tra.2010.02.002

Leu, G., Abbass, H., Curtis, N., 2010. Resilience of ground transportation networks: A case study on Melbourne, in: 33rd Australasian Transport Research Forum. Camberra.

Leung, A., Burke, M., Cui, J., 2017. The tale of two (very different) cities - Mapping the urban transport oil vulnerability of Brisbane and Hong Kong. Transp. Res. Part D Transp. Environ. 1-21. https://doi.org/10.1016/j.trd.2017.10.011

Mattioli, G., Philips, I., Anable, J., Chatterton, T., 2017. Vulnerability to fuel price increases in England Developing an index of vulnerability to motor fuel price increases in England, in: Annual Conference of the University Transport Study Group. University Transport Study Group, Dublin, Ireland. 
Newman, P., Kenworthy, J., 2011. ' Peak Car Use ': Understanding the Demise of Automobile Dependence. World Transp. Policy Pract. 17, 31-45.

Rockefeller Foundation, n.d. 100 Resilient Cities [WWW Document]. URL https://www.100resilientcities.org/ (accessed 8.17.18).

Saunders, M.J., da Silva, A.N.R., 2009. Reducing urban transport energy dependence: A new urban development framework and GIS-based tool. Int. J. Sustain. Transp. 3, 71-87. https://doi.org/10.1080/15568310701648037

Saunders, M.J., Kuhnimhof, T., Chlond, B., da Silva, A.N.R., 2008. Incorporating transport energy into urban planning. Transp. Res. Part A Policy Pract. 42, 874-882. https://doi.org/10.1016/j.tra.2008.01.031

Serulle, N., Heaslip, K., Brady, B., Louisell, W., Collura, J., 2011. Resiliency of Transportation Network of Santo Domingo, Dominican Republic. Transp. Res. Rec. J. Transp. Res. Board 2234, 22-30. https://doi.org/10.3141/2234-03

Stamos, I., Mitsakis, E., Salanova, J.M., Aifadopoulou, G., 2015. Impact assessment of extreme weather events on transport networks: A data-driven approach. Transp. Res. Part D Transp. Environ. 34, 168-178. https://doi.org/10.1016/j.trd.2014.11.002

Stanford University, n.d. Stanford Urban Resilience Initiative [WWW Document]. URL http://urbanresilience.stanford.edu/ (accessed 8.17.18).

United Nations, 2016. Sustainable development goals - United Nations [WWW Document]. URL https://www.un.org/sustainabledevelopment/sustainabledevelopment-goals/ (accessed 8.17.18).

University of Warwick, n.d. Resilient Cities Laboratory [WWW Document]. URL https://warwick.ac.uk/fac/soc/rcl/ (accessed 8.17.18).

Walker, B., Holling, C.S., Carpenter, S.R., Kinzig, A., 2004. Resilience, Adaptability and Transformability in Social - ecological Systems. Ecol. Soc. 9, 5. https://doi.org/10.1103/PhysRevLett.95.258101

Walker, J., Cooper, M., 2011. Genealogies of resilience: From systems ecology to the political economy of crisis adaptation. Secur. Dialogue 42, 143-160. https://doi.org/10.1177/0967010611399616 
